\title{
RELAÇÃO ETNOBOTÂNICA DOS PROPRIETÁRIOS RURAIS DO MUNICÍPIO DE URUPEMA, SC, COM RECURSOS FLORESTAIS
}

\author{
Renata Diane Menegatti ${ }^{1}$, Pedro Higuchi ${ }^{2}$, Ana Carolina da Silva ${ }^{2}$, João Fert Neto ${ }^{2}$, Jean Correia ${ }^{1}$, \\ Alisson Mello Munaretti ${ }^{1}$, Paulo Victor Berri ${ }^{1}$ \\ ${ }^{1}$ Eng. Florestal, UDESC, Lages, SC, Brasil - renata.d.menegatti@ gmail.com; jean_korreia @ hotmail.com; alisson@ florestal.eng.br; \\ paulo.berri@yahoo.com.br \\ ${ }^{2}$ Eng. Florestal, Dr., Depto. de Engenharia Florestal, UDESC, Lages, SC, Brasil - carol_sil4@yahoo.com.br; higuchip@gmail.com; \\ a2jfn@cav.udesc.br
}

Recebido para publicação: 12/11/2012 - Aceito para publicação: 25/04/2014

\begin{abstract}
Resumo
O presente estudo teve como objetivo caracterizar a relação etnobotânica de proprietários rurais do município de Urupema, SC, com recursos florestais. Para isso, foram realizadas entrevistas, em cada uma das 35 propriedades amostradas, sobre as principais fontes de renda e sobre as principais espécies florestais utilizadas. O uso das espécies foi analisado por meio do Nível de Fidelidade (NF) e da Porcentagem de Concordância quanto aos Usos Principais (CUP). As fontes de renda relatadas com maior frequência foram a pecuária, a fruticultura e a aposentadoria. Os recursos florestais são utilizados, principalmente, para fins de alimentação e energético. Todas as espécies citadas apresentaram elevado NF ( $\geq 97 \%$ ) e a Araucaria angustifolia (Bertol.) Kuntze é a espécie de maior valor de CUP (97,06\%), por ser utilizada por quase a totalidade dos entrevistados (34), sempre para os mesmos fins. Os resultados demonstraram que a maioria dos entrevistados (83\%) não obtém renda das florestas naturais, mesmo com quase metade $(47 \%)$ tendo citado que seria possível sustentar a família por meio da exploração dos recursos florestais nativos. Dentre os recursos florestais explorados, destacou-se a extração de pinhão como fonte de renda.

Palavras-chave: Floresta com Araucária; Planalto Catarinense; etnobotânica; produtores rurais.
\end{abstract}

\begin{abstract}
Ethnobotanical connections of rural landowners in the municipality of Urupema, SC, with forest resources. The present research aimed to characterize the ethnobotanical connections of rural landowners in the municipality of Urupema, SC, with their use of forest resource. In order to do that, we conducted interviews, in each of the 35 surveyed properties, focusing the main source of income as well as the main used tree species. The species usages were analyzed by the Fidelity Level (NF) and Percentage of Main Use Concordance (CUP). The most frequent sources of income were livestock, fruit culture and retirement. The forest resources are mainly used as food and energy. All cited species revealed elevated values of NF $(\geq 97 \%)$, and the more elevated value of CUP was observed for Araucaria angustifolia (Bertol.) Kuntze (97,06\%), as such species had been reported by almost the totality of farmers, always for the same purpose. The results revealed that most of the interviewees $(83 \%)$ do not get income from natural forests, even with almost half $(47 \%)$ of them considering that it would be possible to sustain their family by native forest resources exploitation. Among the exploited forest resources, the extraction of pine nuts stood out as income source. Keywords: Araucaria Forest; Planalto Catarinense; forest resource usages; ethnobotany, farmers.
\end{abstract}

\section{INTRODUÇÃO}

O processo histórico de ocupação de terras no Planalto Catarinense, assim como nas demais regiões do Bioma da Mata Atlântica, resultou na fragmentação florestal e em mudanças florísticas e estruturais na vegetação original, principalmente devido à extração predatória de espécies de interesse madeireiro e avanço de atividades agropecuárias. A implementação do Código Florestal no final da década de 60, que regulamentou o uso da terra e restringiu o corte de florestas em áreas de preservação permanente e de reserva legal, e, mais recentemente, da Lei da Mata Atlântica, favoreceu o 
desenvolvimento das florestas secundárias na região, que são aquelas formadas a partir da recomposição da vegetação preexistente após um distúrbio (GLENN-LEWIN; VAN DER MAAREL, 1992).

No entanto, a expansão recente da floresta sobre áreas previamente desmatadas é vista como um problema por proprietários rurais, uma vez que ocorre em áreas que são utilizadas de forma produtiva. Diante desse cenário de conflito, se torna imprescindível a realização de estudos que tenham como meta entender a relação etnobotânica entre a população rural e os remanescentes florestais, de forma a subsidiar estratégias de uso sustentável dos recursos florestais, favorecendo, assim, tanto as comunidades rurais quanto o meio ambiente.

Nesse sentido, caracterizar essa relação é fundamental, uma vez que as populações locais se caracterizam pela dependência do uso dos recursos naturais, a partir do qual constroem um modo de vida particular, e pelo conhecimento aprofundado dos ciclos naturais, que se reflete na elaboração de sistemas de manejo desses recursos. Essas populações também se diferenciam por permanecer e ocupar esse território por várias gerações e por exercer atividades de subsistência, mais ou menos desenvolvidas, contribuindo ou não com o mercado local e regional (DIEGUES; NOGARA, 1996).

O uso de recursos florestais por essas comunidades pode ser analisado por meio da etnobotânica, que é o campo da ciência que visa o estudo da interação entre as populações e a flora local, abrangendo o conhecimento, as formas de uso e manejo das plantas e os diferentes nomes pelos quais elas são conhecidas (ALEXIADES, 1996). Pesquisas nessa área podem subsidiar trabalhos sobre o uso sustentável da biodiversidade, por meio do aproveitamento e valorização do conhecimento popular das sociedades humanas (FONSECA-KRUEL; PEIXOTO, 2004).

Estudos sobre a relação etnobotânica dos proprietários rurais do município de Urupema, SC, são inexistentes. No entanto, eles são importantes em um município com grande parte da população rural e cujos remanescentes florestais, representantes da Mata Atlântica, possuem grande importância biológica na manutenção da flora e fauna da região e proteção dos cursos de água. Assim, o presente estudo teve como objetivo identificar e analisar como as atividades produtivas e de renda dos produtores rurais no município de Urupema, SC, se relacionam com o uso dos recursos florestais.

\section{MATERIAL E MÉTODOS}

O estudo foi realizado no município de Urupema, localizado no Planalto Serrano do estado de Santa Catarina, Brasil. De acordo com o censo oficial, a população atual é de 2.482 habitantes (INSTITUTO BRASILEIRO DE GEOGRAFIA E ESTATÍSTICA (IBGE), 2010), dos quais 50,4\% vivem no meio rural, praticando uma agricultura baseada na mão de obra familiar. As principais atividades extrativistas do município são erva-mate, vime e pinhão. Como atividade produtiva tradicional, destaca-se a pecuária de corte e de leite, assim como a fruticultura de clima temperado, mais recentemente. O município foi escolhido por possuir uma população rural relativamente grande, remanescentes florestais de importância biológica na manutenção da flora e fauna da região e na proteção dos cursos de água. É uma região que sofreu intensa exploração florestal durante o chamado "ciclo da madeira", nos anos 1950 e 1960, e cuja expansão agrícola é recente.

$\mathrm{Na}$ relação entre proprietários rurais e os recursos florestais, foram analisados os aspectos relacionados à fonte de renda familiar, à importância relativa dos recursos florestais para a renda e às mudanças percebidas pelos produtores sobre o uso desses recursos. A abordagem teórico-metodológica dessa análise teve como ponto de partida a ideia de sócio-lógica, desenvolvida pelos autores da Teoria do Ator Rede (TAR) (CALLON, 1986; LAW, 1992; ASSIS, 2000), a qual propõe uma abordagem que analisa os atores como sendo livres para estabelecerem as mais diferentes associações e, assim, comporem a sua própria sócio-lógica, ou seja, uma racionalidade que não necessariamente é a racionalidade da tecnociência, ou da lógica econômica, ou ainda da legislação florestal, no sentido estrito, mas sim uma racionalidade formada por elementos associados a partir da vivência de cada ator, determinando assim a sócio-lógica (ou lógica social) do uso das espécies florestais. É a partir dessa racionalidade que os atores se autodefinem, ou estabelecem a sua própria identidade.

A metodologia proposta pela TAR parte da injunção de "seguir os atores" e verificar o que eles dizem deles mesmos, dos outros e das ligações que estabelecem com o mundo, tomando cada ator como uma rede em relação aos outros atores, humanos e não humanos (estes, chamados de actantes). A TAR propõe a pontualização dessas relações ou ligações, ou seja, um ator define os outros e se define em 
relação a eles apenas pelos seus pontos de ligação. Assim, por exemplo, embora uma floresta seja constituída de uma complexidade de relações ecológicas, de usos, de uma legislação, de uma história, em termos analíticos, para um determinado ator ela é apenas aquilo que a liga a ele, ator. Em termos operacionais da pesquisa, significa inquerir, através de questionários e da observação direta, o que os atores dizem e fazem a respeito das questões já levantadas: fonte de renda familiar, importância relativa dos recursos florestais para a renda e mudanças percebidas pelos produtores sobre o uso desses recursos.

Para a coleta de dados, durante os anos de 2010 e 2011, foram percorridas as principais vias rurais do município, sendo utilizado o método de pesquisa sociológica de comunidades conhecido como "bola-de-neve" (BAILEY, 1984). Nesse método, o primeiro entrevistado serve com informante para identificar outros a serem entrevistados, sendo que o processo se repete até que todos os informantes formem uma rede de atores com vínculos sociais entre si. Dessa forma, foi selecionado um total 35 informantes (Figura 1), que corresponderam a 10\% de todas as propriedades rurais do município (353). Quando não era possível a realização da entrevista em uma das propriedades indicadas, devido à impossibilidade de acesso ou quando os proprietários não se encontravam presentes, era tomada para o estudo a propriedade espacialmente mais próxima.

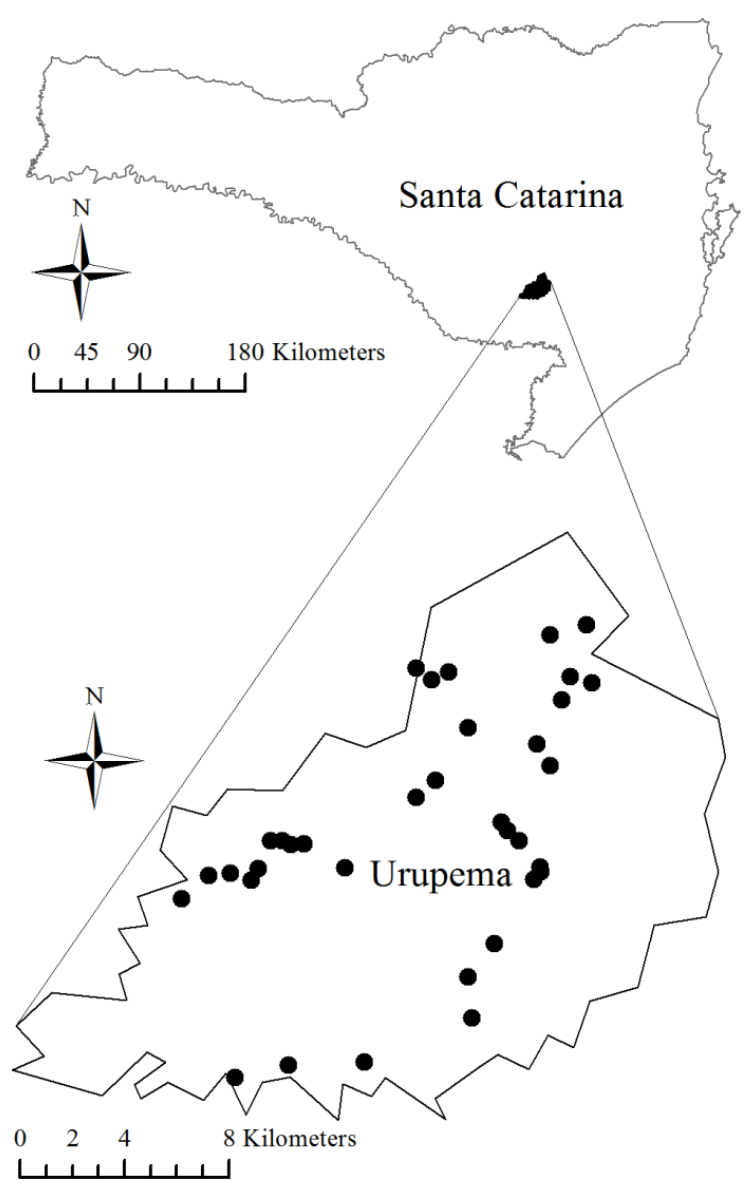

Figura 1. Localização das propriedades rurais selecionadas para o estudo socioeconômico e do uso de espécies florestais no município de Urupema, SC.

Figure 1. Location of rural properties selected for the socio-economic research and analysis of tree species usage in the municipality of Urupema, SC.

Em cada residência selecionada, foram aplicadas entrevistas diretas semiestruturadas, com questões norteadoras do tipo abertas e fechadas (AMOROZO, 2002), sobre a idade dos entrevistados, número de membros familiares moradores em cada propriedade, as principais fontes de renda, sobre a 
possibilidade de sustentar a família por meio da utilização dos recursos florestais, sobre as espécies florestais utilizadas, sobre o manejo da floresta nativa e sobre as mudanças ambientais observadas por eles com o passar do tempo. Durante as entrevistas, buscou-se fazer também a observação direta do uso de recursos florestais nativos e o seu emprego nas unidades de produção agropecuária.

Foram calculados, para cada espécie citada, o Nível de Fidelidade (NF), o Fator de Correção (FC) e a Porcentagem de Concordância quanto aos Usos Principais (CUP), de acordo com a metodologia utilizada por Amaral e Guarim Neto (2008), proposta por Friedman et al. (1986). Os cálculos se deram da seguinte forma:

$$
N F=\left(\frac{I P}{I U}\right) \times 100
$$

em que: IP=número de pessoas citando o uso principal

$\mathrm{IU}=$ número de entrevistados que citou o uso da espécie. Neste caso, o uso principal foi considerado aquele mais citado entre os entrevistados (alimentação, comércio, lenha, palanques e construções e outros).

$$
C U P=N F \times F C
$$

em que: $\mathrm{FC}$ = fator de correção, calculado como sendo IU/número de entrevistados que citaram a espécie mais mencionada.

Por meio desses índices, procurou-se entender a relação etnobotânica dos proprietários rurais com as espécies arbóreas que ocorrem na região. Enquanto o NF avalia a importância de cada espécie para uma finalidade particular, a CUP identifica a maior ou menor popularidade de uma espécie (FRIEDMAN et al., 1986; FRANÇA, 2006).

\section{RESULTADOS E DISCUSSÃO}

Foram entrevistados 24 homens e 11 mulheres, com idade entre 18 e 75 anos (média $=46$ anos), sendo que cada unidade familiar era composta, em média, por 3,4 indivíduos. A amostragem foi considerada adequada, uma vez que, a partir do $18^{\circ}$ informante, as respostas, em relação ao questionário aplicado, começaram a se repetir. A maior parte dos produtores (83\%) não obtém renda da floresta nativa, sendo a pecuária, a fruticultura e a aposentadoria as principais fontes de renda (Figura 2).

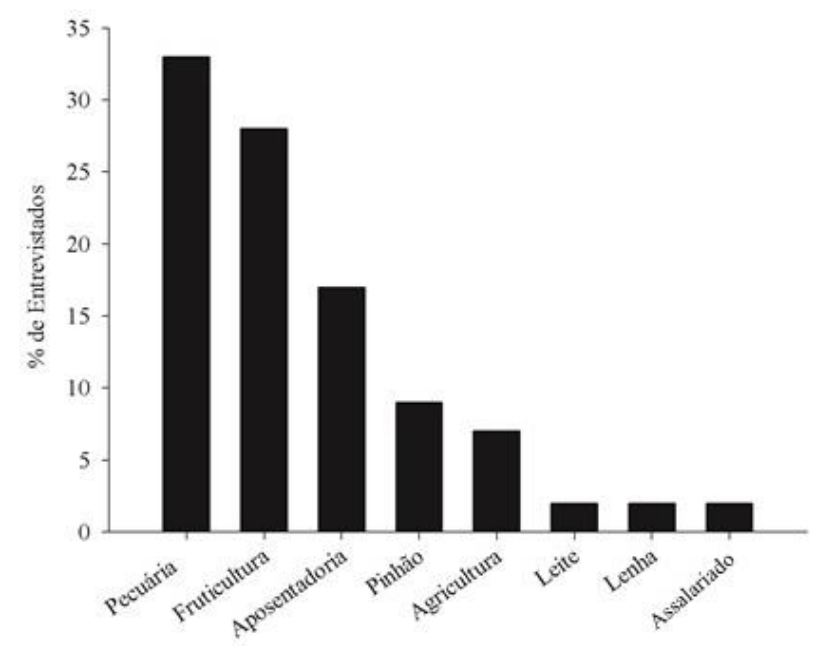

Figura 2. Fontes de renda dos produtores entrevistados na área rural do município de Urupema, SC.

Figure 2. Income sources of farmers interviewed in rural area in the municipality of Urupema, SC. 
Para Salgado (2000), a pecuária na zona rural do planalto serrano é a opção de menor risco, sendo utilizada como uma tradição, mas também resulta em menor rentabilidade devido ao escasso emprego do capital, tecnologia e mão de obra, fatores limitantes para a produtividade. Já a fruticultura é uma das principais fontes de renda do município, pois os pomares de maçã ocupam aproximadamente 447 ha e envolvem 99 fruticultores, sendo sua representatividade tão grande que a produção de maçã em Urupema chega a 16 mil toneladas/ano (RIBEIRO, 2009). Destaca-se, também, que a aposentadoria representa uma importante fonte de renda, refletindo a elevada faixa etária da população rural. Assim, como é apontado no trabalho realizado por Sacco dos Anjos et al. (2004), grande parte dos entrevistados recebe a aposentadoria e utiliza esses recursos como mecanismo indireto de financiamento da agricultura, muitas vezes servindo como uma espécie de "seguro agrícola".

Quase metade dos entrevistados (47\%) relatou que seria possível sustentar a família por meio da utilização dos recursos florestais, o que indica uma percepção sobre o potencial florestal na área de estudo, embora isso não se reflita nas estratégias produtivas da propriedade. Em um estudo em Lages, também no Planalto Sul Catarinense, Aguiar et al. (2012) encontraram 87 espécies arbóreas em um remanescente florestal, sendo que, destas, somente cinco espécies não possuíam utilização registrada, destacando o grande potencial de utilização de produtos madeireiros e não madeireiros que as florestas da região possuem. Os entrevistados revelaram ter assimilado um discurso que faz uma menção genérica à conservação dos recursos naturais e à sustentabilidade, como: "tem que preservar", "tem que deixar para os netos", "sem um mato aí não tem água". Porém, isso não impede que práticas que provocam a degradação da floresta continuem sendo utilizadas no limiar da legislação, como a entrada do gado na floresta, inclusive em APP (Áreas de Preservação Permanente), o corte do sub-bosque, o uso do fogo e o corte de regeneração de araucárias no campo, entre outras. Por outro lado, revelam um desinteresse, sob o ponto de vista econômico, na manutenção e expansão das áreas florestais - alegam, inclusive, que uma terra com floresta vale menos que uma terra desmatada, o que pode ser confirmado pela valoração das terras desmatadas no mercado regional (FLORIANI, 2007). Já a pecuária e a fruticultura permitem uma renda maior e livre de preocupações legais. As restrições legais são apontadas como maior fator impeditivo do uso da floresta como fonte de renda, pela impossibilidade do corte para uso madeireiro, restrições trabalhistas para o corte da erva-mate, cujo trabalho é terceirizado, e também pela carência de mão de obra jovem nas propriedades para atividades como a colheita do pinhão.

Assim, se for seguida a racionalidade da tecnociência florestal, o uso sustentável dos recursos madeireiros e não madeireiros poderia ser considerado uma importante estratégia de conservação do meio ambiente, por meio da manutenção e aumento de áreas florestais, favorecendo a produção de água nas cabeceiras dos rios e nos banhados, fixando o $\mathrm{CO}_{2}$ atmosférico e ainda constituindo uma importante fonte de renda para os proprietários rurais do município de Urupema. No entanto, as associações que esses proprietários fazem conduzem para outra racionalidade, que é a da diminuição das áreas florestais e a expansão da pecuária e da fruticultura, sem deixar de reproduzir um discurso sobre a necessidade da preservação. Contribui com essa racionalidade o passado histórico da região e as representações sociais a respeito das atividades produtivas, as quais atribuem um maior status social ao pecuarista em detrimento de uma identidade de mateiro, roceiro, coletor de pinhão ou, pior ainda, de ervateiro, que é um assalariado por tarefa. No que se refere à fruticultura, ocorre um fenômeno semelhante ao que estudou Pereira (2004) para o caso de São Joaquim, município vizinho. Destaca ele que, além dos fatores técnicos, um fator de ordem social, que se refere ao status conferido pela sociedade local às pessoas que se dedicavam a essa atividade, funcionou como uma espécie de "cimento" entre os fatores de ordem técnico-científica: a cultura e o poder local, conferindo legitimidade social à passagem de pecuarista para fruticultor - "plantar maçã, além de se ter possibilidade de ganhar dinheiro, dá status".

Isso não significa que as atividades florestais não tivessem relevância no passado histórico, pelo contrário. Como apontam Floriani e Fert Neto (2011), houve um conjunto bastante amplo de formas de uso florestal que caracterizaram o processo de formação da paisagem e dos modos de vida na região. Alguns exemplos são a exploração de lenha, madeira para uso não beneficiada industrialmente, madeiras para uso específico (cabos de ferramentas), nós de pinho, xaxim, erva-mate, escoras para a construção civil e o uso alternado da terra florestal na prática da coivara. Usos esses que, embora hoje sejam pouco significativos em termos econômicos, tiveram uma grande relevância em outros períodos. Esse conjunto de usos e atividades florestais compartilha elementos que os tornam tão abrangentes e duráveis quanto aqueles que foram considerados típicos da região, como a pecuária e a exploração industrial da araucária no passado, e a fruticultura e a silvicultura no presente. Contudo, a marginalidade dos grupos sociais que davam suporte a essas atividades pode ter contribuído para seu esquecimento pela história, pois também não conseguiram perpetuar suas formas de vida, seus símbolos, sua linguagem (RIBEIRO DE JESUS, 1991). 
Quanto à renda obtida a partir dos produtos de florestas nativas, o pinhão obtido da Araucaria angustifolia (Bertol.) Kuntze é o principal recurso da região. De acordo com Silveira et al. (2011), a cultura de venda e compra do pinhão representa um importante complemento para o orçamento de inúmeras famílias, pois os vendedores se organizam todos os anos para a venda e contam com esse ganho extra. Ressalta-se também que, para fins domésticos de recursos florestais, é comum o uso da lenha (87\% dos entrevistados), a extração de goiaba-serrana (Acca sellowiana (O. Berg) Burret) (10\% dos entrevistados), a produção de palanque, também conhecidos como moirões ( $8 \%$ dos entrevistados) e a extração de erva-mate (Ilex paraguariensis A. St.-Hil.) (3\% dos entrevistados). Entre as principais espécies florestais utilizadas como lenha, $40 \%$ citaram as vassouras (Baccharis spp.), 23\% a bracatinga (Mimosa scabrella Benth), 19\% a aroeira (Schinus terebinthifolius Raddi) e 10\% utilizam o eucalipto (Eucalyptus spp.) produzido na propriedade. Por se tratar de uma espécie típica da região, destaca-se o potencial de exploração econômica da goiaba-serrana. Segundo Barni et al. (2004), essa espécie tem exigências climáticas específicas, coincidindo no Brasil com as regiões preferenciais de cultivo da macieira, o que indica o seu cultivo nas regiões mais frias, como a região da Serra Catarinense, incluindo o município de Urupema.

A tabela 1 apresenta os valores obtidos na análise quantitativa da importância relativa das espécies, por meio dos cálculos do NF (Nível de Fidelidade) e Concordância quanto aos Usos Principais (CUP). Os valores do NF foram elevados, com o valor mínimo de 97\% para Araucaria angustifolia, o que indica que a população rural associou a espécie ao seu principal uso (Tabela 1). Apenas um entrevistado não associou Araucaria angustifolia ao seu principal uso, que é a extração de pinhão, o que resultou no valor abaixo de $100 \%$. Devido ao elevado valor de NF e de quase a totalidade dos entrevistados (34) terem citado a utilização dessa espécie, a araucária teve o valor mais elevado de CUP $(97,06 \%)$. A segunda espécie com o maior valor de CUP foi a macieira, citada por 13 entrevistados, sendo que todos estes citaram seu principal uso, o que ilustra, novamente, a importância da fruticultura na região.

Tabela 1. Usos principais e concordância quanto ao uso das espécies florestais citadas pelos informantes da zona rural de Urupema (SC). Usos: alimentação (a), comércio (b), lenha (c), palanques e construções (d) e outros (e). IU: número de entrevistados que citou o uso da espécie; IP: número de pessoas citando o uso principal; NF: Nível de Fidelidade; FC: Fator de Correção; CUP: Concordância quanto ao Uso Principal.

Table 1. Main uses and concordance related to tree species referred by informants of Urupema (SC) rural areas. Usage: food (a), trade (b), firewood (c), fence posts and buildings (d), and other (e). IU: number of interviewees referred the use of the species; IP: number of interviewees referred the main usage; NF: Fidelity Level; FC: Correction Factor; CUP: Main Usage Concordance.

\begin{tabular}{|c|c|c|c|c|c|c|c|c|}
\hline Espécie (nome popular) & Usos & $\mathbf{I U}$ & $\begin{array}{l}\text { Número de } \\
\text { usos citados }\end{array}$ & Uso principal & IP & $\begin{array}{l}\text { NF } \\
(\%)\end{array}$ & FC & $\begin{array}{l}\text { CUP } \\
(\%)\end{array}$ \\
\hline $\begin{array}{l}\text { Araucaria angustifolia (Bertol.) Kuntze } \\
\text { (araucária) }\end{array}$ & $a, b, d$ & 34 & 2 & Alimentação & 33 & 97 & 1,00 & 97,00 \\
\hline Pyrus malus L. (macieira) & $a, b, c$ & 13 & 2 & Alimentação & 13 & 100 & 0,38 & 38,00 \\
\hline Mimosa scabrella Benth. (bracatinga) & $\mathrm{c}, \mathrm{d}$ & 12 & 2 & Energia & 12 & 100 & 0,35 & 35,00 \\
\hline $\begin{array}{l}\text { Vernonanthura discolor (Spreng.) H.Rob. } \\
\text { (vassourão-preto) }\end{array}$ & $\mathrm{c}, \mathrm{d}$ & 11 & 2 & Energia & 11 & 100 & 0,32 & 32,00 \\
\hline $\begin{array}{l}\text { Schinus terebinthifolius Raddi (aroeira- } \\
\text { vermelha) }\end{array}$ & $\mathrm{c}, \mathrm{d}$ & 8 & 1 & Energia & 8 & 100 & 0,24 & 24,00 \\
\hline $\begin{array}{l}\text { Piptocarpha angustifolia Dusén (vassourão- } \\
\text { branco) }\end{array}$ & $\mathrm{c}, \mathrm{d}$ & 8 & 2 & Energia & 8 & 100 & 0,24 & 24,00 \\
\hline Eucalyptus spp. (eucalipto) & $\mathrm{b}, \mathrm{c}, \mathrm{d}$ & 6 & 2 & Madeireira & 6 & 100 & 0,18 & 18,00 \\
\hline $\begin{array}{l}\text { Acca sellowiana (O.Berg) Burret (goiabeira- } \\
\text { serrana) }\end{array}$ & a & 3 & 1 & Alimentação & 3 & 100 & 0,09 & 9,00 \\
\hline Lithraea brasiliensis March. (bugreiro) & $\mathrm{c}, \mathrm{d}$ & 2 & 1 & Energia & 2 & 100 & 0,06 & 6,00 \\
\hline Ilex paraguariensis A.St.-Hil. (erva-mate) & $a, b, e$ & 1 & 2 & Alimentação & 1 & 100 & 0,03 & 3,00 \\
\hline Ocotea pulchella Mart. (canela-lageana) & $\mathrm{D}$ & 1 & 1 & Madeireira & 1 & 100 & 0,03 & 3,00 \\
\hline Pyrus communis L. (pereira) & $a, b$ & 1 & 1 & Alimentação & 1 & 100 & 0,03 & 3,00 \\
\hline Pinus spp. (pinus) & $\mathrm{b}, \mathrm{d}$ & 1 & 1 & Madeireira & 1 & 100 & 0,03 & 3,00 \\
\hline
\end{tabular}


A araucária é a principal referência que os proprietários rurais têm em relação à floresta ( $28 \%$ dos entrevistados). Isso se dá pelo fato de essa espécie ter sido intensamente explorada no passado recente, devido às características de sua madeira, por dominar a fisionomia florestal e por apresentar o maior valor de CUP dentre as espécies citadas (Tabela 1). No entanto, a restrição de exploração sustentável de araucária cria um sentimento de indignação entre os proprietários rurais, como relatado por Pinto (2009), pelo fato de que muitos assistem passivamente a morte de pinheiros, muitas vezes plantados por eles próprios, sem que possam aproveitá-los livremente em função da legislação vigente altamente proibitiva ao uso da espécie. Para outros $20 \%$ dos entrevistados, a floresta está associada à natureza e à sua preservação, o que é um indicativo de pouco reconhecimento das florestas no fornecimento e na manutenção de serviços ambientais.

A expansão da área florestal sobre a área de campo é perceptível pelos proprietários rurais, uma vez que a maioria dos entrevistados relatou esse processo ocorrendo nos últimos anos. Essa expansão se deu, principalmente, em função da implementação do Código Florestal a partir do final da década de 60 . No entanto, devido às restrições de uso, essa expansão cria uma situação de conflito nas propriedades rurais, pois a área de floresta compete com as áreas produtivas, como a pecuária e a fruticultura. $\mathrm{O}$ cenário atual de forte restrição de uso dos recursos florestais é um dos fatores que podem explicar a utilização de práticas não sustentáveis para a manutenção da floresta, como a roçada do sub-bosque da floresta (48\% dos entrevistados), com o intuito de favorecer a entrada do gado no interior das áreas de floresta. Conforme Wilson (1994), uma vez dentro do fragmento, o gado alimenta-se das folhas, frutos e sementes palatáveis de algumas espécies vegetais, além de pisotear as plântulas e compactar o solo, dificultando a germinação das sementes e o crescimento das plântulas. Os efeitos do pastoreio nas populações de Araucaria angustifolia variam em função das características ambientais e da intensidade e frequência de pastoreio (SAMPAIO; GUARINO, 2007).

\section{CONCLUSÃO}

A análise da caracterização socioeconômica e do uso das espécies florestais no município de Urupema permite as seguintes conclusões:

- Há uma percepção da necessidade de preservar as florestas e o meio ambiente, pelo menos no discurso, e de que, para metade dos entrevistados, a floresta poderia gerar renda. No entanto, isso não se traduz em práticas produtivas, devido às restrições da legislação ambiental, principalmente pela proibição do corte de espécies madeireiras. A percepção de que a floresta poderia gerar renda com a exploração da madeira pode estar relacionada com a memória histórica de quando a exploração da araucária, nos anos 1950 e 1960, proporcionou renda monetária para pequenos proprietários até então inexistente, mas estima-se que hoje dificilmente proporcionariam uma quantidade de renda significativa e permanente. Com as restrições legais, a área com cobertura florestal tende a aumentar, mas a degradação das florestas continua através de práticas degradadoras, como raleio do subbosque, gado na floresta e roçada da regeneração de araucária nos campos. Práticas estas que, por serem difusas, escapam ao controle efetivo da legislação ou fiscalização ambiental.

- A não adoção de práticas produtivas florestais pode ser explicada pelas relações que os agricultores fazem entre floresta, complicações legais e trabalhistas, pouca renda, baixo status e falta de mão de obra, principalmente jovem. Uma associação favorável ao desenvolvimento da propriedade é a de renda, pecuária, tradição, fruticultura, status e expansão de áreas desmatadas, além da aposentadoria, o que leva a uma racionalidade desfavorável à valorização da floresta como um recurso, passando a ser um obstáculo ao desenvolvimento da propriedade.

- Sendo a araucária a principal referência dos proprietários rurais, o manejo adequado da espécie poderia conduzir a uma política florestal que transformasse a floresta de um obstáculo em um recurso, através do estabelecimento de bases técnicas e legais, e desburocratizadas, para o uso dela em propriedades familiares. O fortalecimento da cadeia produtiva do pinhão, com certificação, melhoria no sistema de colheita, associativismo e outras medidas, seria também positivo para a valorização da espécie. Além disso, o enriquecimento das áreas florestais e o aprofundamento de estudos sobre o uso de outros produtos não madeireiros possíveis de vir a agregar renda às propriedades auxiliaria na valorização da floresta. 
- Por fim, a construção de uma identidade positiva de usuário da floresta, como, por exemplo, o de produtor ou manejador de pinhão, com um status próximo ao de pecuarista ou fruticultor, criaria uma tendência de revalorização das áreas florestais, tanto econômica quanto socialmente.

\section{REFERÊNCIAS}

AGUIAR, M. D.; SILVA, A. C.; HIGUCHI, P.; NEGRINI, M.; FERT NETO, J. Potencial de uso de espécies arbóreas de uma floresta secundária em Lages, Santa Catarina. Revista de Ciências Agroveterinárias, Lages, v. 11, p. 238 - 247, 2012.

ALEXIADES, M. Selected guidelines for ethnobotanical research: a field manual. New York: The New York Botanical Garden, 1996. 306 p.

AMARAL, C. N.; GUARIM NETO, G. Os quintais como espaços de conservação e cultivo de alimentos: um estudo na cidade de Rosário do Oeste (Mato Grosso, Brasil). Boletim do Museu Paraense Emílio Goeldi. Ciências Humanas, Belém, v. 3, p. 329 - 341, 2008.

AMOROZO, M. C. M. Agricultura tradicional: espaços de resistência e o prazer de plantar. In: AlbUQUerQue, U. P.; AlVES, Â. G.; SILVA, A. C. B.; SILVA, V. A. Atualidades em Etnobotânica e Etnoecologia. Recife, 2002. p. 123 - 131.

ASSIS, J. P. Ciência em ação: como seguir os cientistas e engenheiros sociedade afora. Interface, Botucatu, v. 4, p. 145 - 146, 2000.

BAILEY, K. Methods of social research. 4. ed. New York: The Free Press, 1994. 588 p.

BARNI, E. J.; DUCROQUET, J. P.; SILVA, M. C.; BEPPLER NETO, R.; PRESSER, R. F. Potencial de mercado para goiaba-serrana catarinense. Florianópolis: EPAGRI, 2004. v. 212. 48 p.

CALLON, M. The sociology of an actor-network: the case of electric vehicle. In: CALLON, M.; LAW, J.; RIP, A. Mapping the dynamics of science and technology. London, 1986. p. 19 - 34.

DIEGUES, A. C.; NOGARA, P. J. O nosso lugar virou parque. São Paulo: NUPAUB/USP, 1996. 165 p.

FLORIANI, G. S. História florestal e sócio-lógica do uso do solo na região dos Campos de Lages no século XX, Santa Catarina. 203 f. Dissertação (Mestrado em Ciências do Solo) - Universidade do Estado de Santa Catarina, Lages, 2007.

FLORIANI, G.; FERT NETO, J. A trajetória do uso do solo por florestas na região dos Campos de Lages. Revista de Ciências Agroveterinárias, Lages, v. 10, p. 93 - 102, 2011.

FONSECA-KRUEL, V. S.; PEIXOTO, A. L. Etnobotânica na Reserva Extrativista Marinha de Arraial do Cabo, RJ, Brasil. Acta Botânica Brasílica, Feira de Santana, v. 18, p. 177 - 190, 2004.

FRANÇA, J. F. Plantas medicinais na comunidade ribeirinha de Nossa Senhora de Aparecida (Silves, AM): um estudo etnobotânico. 102 f. Dissertação (Mestrado em Agronomia Tropical) Universidade Federal do Amazonas, Manaus, 2006.

FRIEDMAN, J.; YANIV, Z.; DAFNI, A.; PALEWITCH, D. A preliminary classification of the healing potential of medicinal plants, based on a rational analysis of an ethnopharmacological field survey among Bedouins in the Negev desert, Israel. Journal of Ethnopharmacology, Amsterdan, v. 16, p. 275 - 187, 1986.

GLENN-LEWIN, D. C.; VAN DER MAAREL, E. Pattern and processes of vegetation dynamics. In: GLENN-LEWIN, D. C.; PEET, R. K.; VEBLEN, T. T. Plant sucession: theory and prediction. London, 1992. p. 11 - 59.

INSTITUO BRASILEIRO DE GEOGRAFIA E ESTATÍSTICA (IBGE). Resultados do Censo 2010. Disponível em: <http://www.ibge.gov.br/home/estatistica/populacao/censo2010/tabelas_pdf/total_ populacao_santa_catarina.pdf $>$. Acesso em: 10/06/2012. 
LAW, J. Notes on the Theory of the Actor-Network: Ordering, Strategy, and Heterogeneity. Systems Practice, New York, v. 5, p. 379 - 393, 1992.

PEREIRA, J. A. Percepção do uso do solo e desenvolvimento rural: um estudo da etnopedologia no planalto sul de Santa Catarina. 150 f. Dissertação (Mestrado em Ciências do Solo) - Universidade do Estado de Santa Catarina, Lages, 2004.

PINTO, G. R. M. Revalorização como forma de garantir a perpetuação do pinheiro brasileiro (Araucaria angustifolia) e da floresta de araucárias. 2009. Disponível em: <http://www.sct.embrapa.br/cdagro/tema05/05tema04.pdf>. Acesso em: 10/04/2012.

RIBEIRO, N. V. Governador abre colheita da maçã e inaugura ampliação de Unidade de Saúde em Urupema. Disponível em: <http://saojoaquimonline.com.br/14/03/2009/governador-abre-colheita-damaca-e-inaugura-ampliacao-de-unidade-de-saude-em-urupema/> . Acesso em: 23/05/2012.

RIBEIRO DE JESUS, S. Formação do trabalhador catarinense: o caso do caboclo do planalto serrano. 176 f. Dissertação (Mestrado em História) - Universidade Federal de Santa Catarina, Florianópolis, 1991.

SACCO DOS ANJOS, F.; GODOY, W. I.; CALDAS, N. V.; GOMES, M. C. Agricultura familiar e políticas públicas: impacto do PRONAF no Rio Grande do Sul. Revista de Economia e Sociologia Rural, Brasília, v. 42, p. 529 - 548, 2004.

SALGADO, S. R. C. O Processo de desenvolvimento rural sustentável de Urupema. In: FARAH, M. F. S.; BARbOZA, H. B. Novas Experiências de Gestão Pública e Cidadania. Rio de Janeiro, 2000. Editora FGV, 2000. p. 3 - 20.

SAMPAIO, M. B.; GUARINO, E. S. G. Efeitos do pastoreio de bovinos na estrutura populacional de plantas em fragmentos de Floresta Ombrófila Mista. Revista Árvore, Viçosa, v. 31, p. 1035 - 1046, 2007.

SILVEIRA, E. R.; JAMHOUR, J.; FERRONATO, M. L.; XAVIER, E; CALGARO, E. V. S. Situação das famílias na extração e comercialização do pinhão no sudoeste do Paraná. Synergismus Scyentifica, Pato Branco, v. 6, p. 1 - 6, 2011.

WILSON, H. D. Regeneration of native forest on Hinewai reserve, Banks peninsula. New Zealand Journal of Botany, Wellington, v. 32, p. 373 - 383, 1994. 
